\title{
Investigation of Developed Thermal Forces in Long Concrete Frame Structures
}

\author{
Mustafa K. Badrah ${ }^{1}$ and Mansour N. Jadid ${ }^{2, *}$ \\ ${ }^{I}$ Faculty of Civil Engineering, University of Aleppo, Aleppo, Syria \\ ${ }^{2}$ Department of Building Science and Technology, University of Dammam, Saudi Arabia
}

\begin{abstract}
The objectives of this paper are to review the modeling and design of concrete frame structures for the changing member-temperature loading case and the section gradient-temperature loading case. In addition, the intensity distribution of internal forces resulting from temperature changes and the factors that cause a decrease or increase in these forces was studied. When the temperature of an object changes positively or negatively, its length increases or decreases according to basic physical laws. If an object subjected to temperature change is restrained, internal compression or tension forces are created. Using temperature equations in a finite element structural analysis software package, deformation and internal forces were calculated for 2-D and 3-D frame buildings. In the member-temperature change loading case, conclusions were reached that no matter how high the structure is, only members such as beams and columns on the lowest two stories are substantially affected, but the greater the length or width of the structure, the greater are the force values on the affected members. In the section gradient-temperature loading case, it was observed that the most affected members were the beams on the upper two levels in addition to the facade columns; however, the output forces and moment values were small and sometimes negligible.
\end{abstract}

Keywords: Frame structures, reinforced concrete, member-temperature loading, section-gradient loading, thermal effects, thermal loading.

\section{INTRODUCTION}

Understanding the behavior of structures under thermal effects is essential, but this topic remains controversial in the field of structural concrete. Although advances in analytical modeling have enabled structural designers to develop sophisticated models, actual structural behavior under thermal effects still requires further investigation. A 2-D nonlinear structural analysis of a reinforced concrete simple beam to determine changes in the material properties of the concrete and reinforcements with increasing temperatures has been carried out [1]. A comparison was made between the results of the proposed nonlinear model and those of the Eurocode, which showed an acceptable correlation.

A theoretical explanation for the key phenomena which govern the behavior of composite framed structures in fire was reported [2]. This theoretical was developed in parallel with a large scale computational study as a part of a research project. The key discoveries in this research created an understanding that composite framed structures have enormous reserves of strength when they use large displacement configurations, and it is these and not material degradation that control the structural response in case of fire. Two further observations are that thermal loads imposed on reinforced

*Address correspondence to this author at the P. O. Box 30973, Al-Khobar 31952, University of Dammam, Dammam, Saudi Arabia;

Tel: 00966505873655; Fax: 00966135550135; Email: mnjadid@yahoo.com concrete structure can introduce major deformations and that the internal forces created in a structure by thermal loads depend heavily on structural stiffness [3]. These observations were based on three large scale reinforced concrete portable frame models. Designers are usually eager to design buildings so that after a severe fire, the structure can be repaired. Generally, however, it was observed that a large fire, especially in tall buildings, can easily cause the building to lose stability or even collapse. Thermal analysis [4] was used to incorporate the finite difference method to model the temperature distribution of a reinforced concrete beam maintained at high temperature. For structural analysis, the lumped method was used to calculate the residual bearing capabilities, which included flexural and shear capacities. This study has proposed an original model to predict the residual capabilities of reinforced concrete beams which are exposed to fire. Reinforced concrete slabs for eight largescale specimens were tested under combined thermal and mechanical load conditions [5]. The specimens under investigation were varied in the amount and orientation of the inplane reinforcement provided. A three-phase loading system was used for the investigating of the thermal gradient effects at service and ultimate load conditions. Thermal stress as a factor of the large bridge structure cracks were investigated [6]. Additional internal forces, which occur in long concrete frame structures by hydration heat during construction and air temperature change were investigated [7]. The effect of temperature load on structure with elliptic plane shape was 
considered [8]; the results reflect that curvature has an apparent influence on the temperature stress. The researchers studied both cases of the annular structure with and without expansion joints; and concluded that reasonable installation of an expansion joint can decrease the temperature stress of annular structure.

Usually, when the temperature of a body is raised or lowered, the material expands or contracts according to physical material expansion laws. If this expansion or contraction is entirely or partially resisted, stresses are set up in the body. Assuming a fully restrained element subjected to a temperature increase $T$, the thermal compression force is given by [9]:

$\mathrm{P}=\alpha$ TEA

$P=$ resulting axial force

$\alpha=$ coefficient of linear expansion

$T=$ temperature change

$E=$ Young's modulus

$A=$ element area.

Integrating the basic laws for Eq. (1) into a finite element analysis program, deformation under thermal effects in sophisticated structural models can be computed, and actions such as moments and forces can be estimated $[10,11]$. The temperature load creates thermal strain in the frame element. This strain is given by the product of the material coefficient of thermal expansion, $\alpha$, and the temperature change of the element, $T$. Temperature load produces axial strains in each column and beam subject to thermal load. Consequently, some members may have axial load and/or moment internal output forces because of the constraints of the movement at the foundation level and in the fully-rigid frame joints. Architectures tend to utilize available spaces of properties. They prefer if they can provide longer building dimensions without (or with least number of) construction joints with coordination with structural designers. Construction joints can be used but they have two major drawbacks. They may diminish the aesthetics of the building and they need higher cost maintenance during the lifetime of the structure; for structure with rectangular shape. Questions have been raised by the authors about which members are most affected by temperature loading, how the temperature effect is related to the structural dimensions, and how significant are the resulting forces. These questions are studied in detail in this paper.

\section{CASES OF TEMPERATURE CHANGE LOADING}

Design of structures for temperature change loading includes two basic fundamental loading cases: member-temperature change and section-gradient-temperature change [12]. The analytical models in this section assume linear static analysis with isotropic concrete material. All tested models are models of skeletons with frames without walls. The reason is to focus on the effects of temperature change in the structure by changing limited parameters (such as structures dimension, temperature change, $T$ ). Existing of walls at one end of the structure causes substantially greater stiffness against lateral displacement.

\subsection{Member-Temperature Change}

The member-temperature change loading case deals with the temperature effect on the structural members as a whole. It is important then to determine the temperature change, $T$, or $\Delta T$. This was assumed to be the difference between the temperature of the concrete during casting season and the extreme low or high temperature to which the structure might be subjected. An accurate determination of this variable depends on weather conditions (structures in open environments experience worse effects than enclosed structures) and on the speed of temperature change between day and night in winter and in summer. Temperature change, $\Delta T$, can be calculated according to Eq. (2) [13]:

$\Delta \mathrm{T}=\operatorname{Max}(\Delta \mathrm{T} 1, \Delta \mathrm{T} 2)$

$\Delta \mathrm{T} 1=\mathrm{T}_{\mathrm{w}}-\mathrm{T}_{\mathrm{m}}$

$\Delta \mathrm{T} 2=\mathrm{T}_{\mathrm{m}}-\mathrm{T}_{\mathrm{c}}$

$T_{m}=$ average temperature during construction season

$T_{w}=$ maximum anticipated temperature during summer season

$T_{c}=$ minimum anticipated temperature during summer season.

\subsection{Section-Gradient-Temperature}

The section-gradient-temperature loading case deals with the effect of temperature changes between the inside and outside of a structure, for instance, a temperature analysis of an office block equipped with air conditioning and heating systems. Inside the building, the temperature is around $20^{\circ} \mathrm{C}$, while the outside could reach as high as $50^{\circ} \mathrm{C}$ during summer and as low as $-20^{\circ} \mathrm{C}$ during winter. This results in a temperature gradient between the outer side and the inner side of the façade and roof elements, which causes rotations of sections of these elements and hence produces thermal forces.

\section{ACI APPROACH FOR THERMAL LOADING CONSIDERATIONS}

The ACI Building Code Requirements [13] for joints in concrete construction assume a length value for the spacing between two expansion joints (d), without the need to analyze the structure for thermal loading. This length could be as long as $66 \mathrm{~m}$ and is subject to the following rules:

- The allowable length (d) should be reduced by $15 \%$ in the case that the connections between the columns and the foundations are fully fixed instead of pinned connections.

- In the case that the building does not include a heating system, the allowable length should be reduced by $33 \%$.

- In the case that the building does include an HVAC system, the allowable length should be increased by $15 \%$.

- If the building has substantially greater stiffness against lateral displacement at one end of the structure, the allowable length should be decreased by $25 \%$.

It is understood that any structure with a length greater than the allowable length according to the previous rules should be analyzed for thermal loading. 


\section{INVESTIGATIVE STUDY}

\subsection{Member-Temperature Change Loading Case}

A parametric investigation study was carried out by the authors to analyze 3-D frame structures subjected to mem- ber-temperature change loading cases. Group (M1-M7) included seven frame skeletons of lengths between 35 and 65 $\mathrm{m}$, a fixed width of $35 \mathrm{~m}$, and a fixed height of $(6 \times 3.5=21)$ $\mathrm{m}$. Each model was analyzed for seven positive temperaturechange loading cases U1-U7 with $\mathrm{T}=(+10,+15,+20,+25$,

Table 1. Description of Analytical Model Dimensions and Temperature-Change Loading Cases

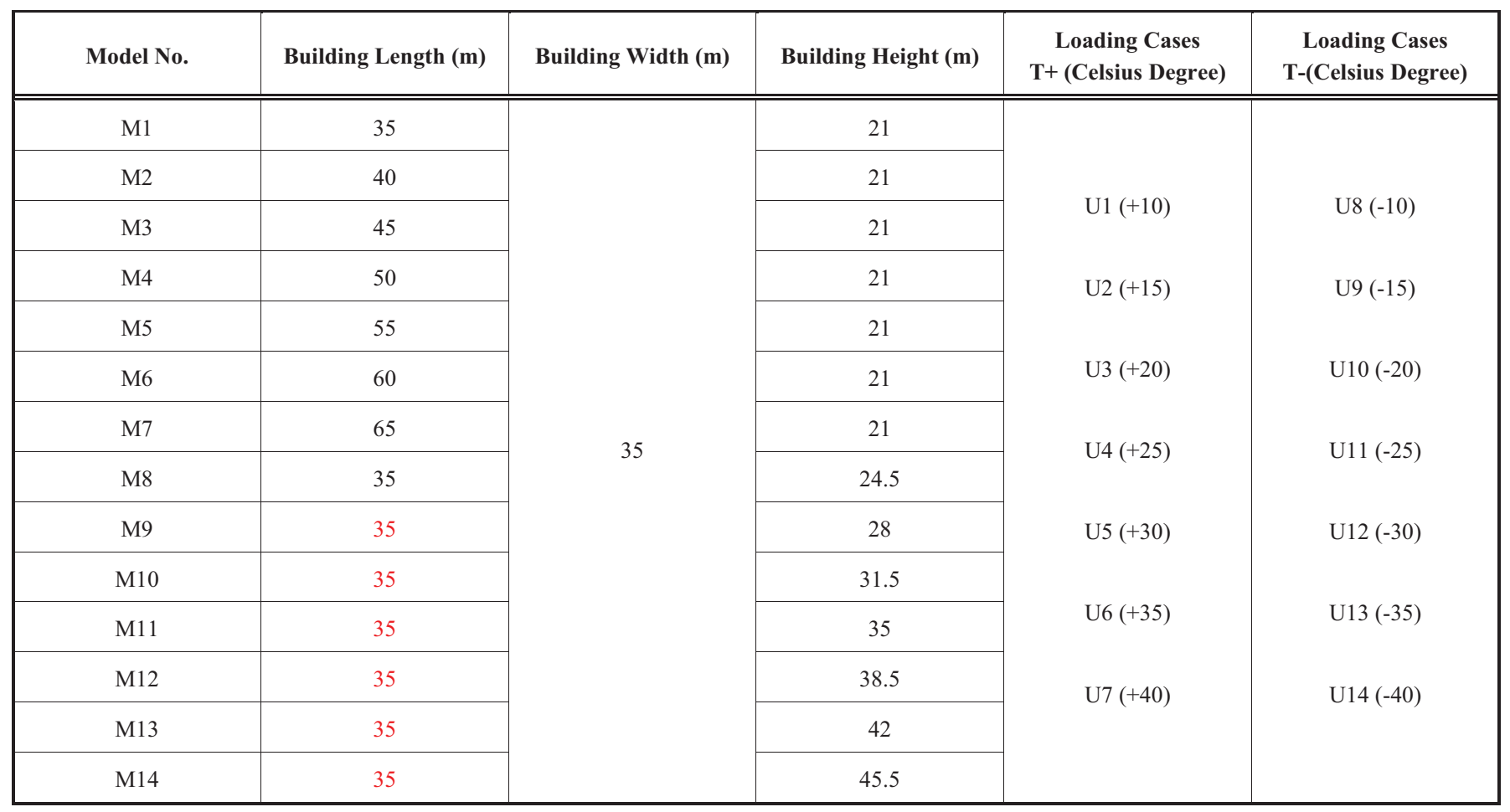

Table 2. Structural Analysis Results of Model M1 for All Loading Cases U1-U14

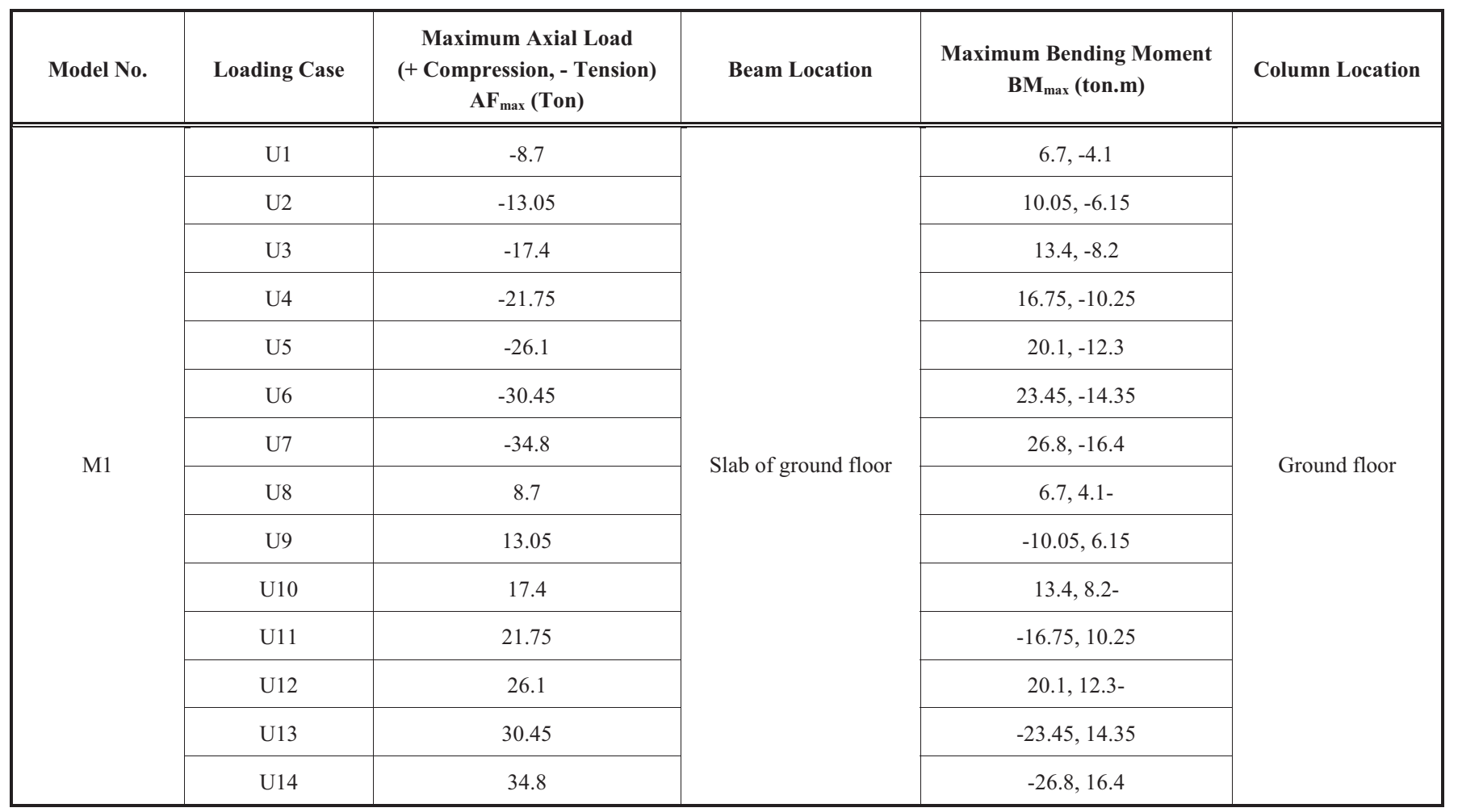


$+30,+35,+40)$ and seven negative temperature-change loading cases U8-U14 with $\mathrm{T}=(-10,-15,-20,-25,-30,-35,-40)$, as shown in Table 1. Group (M8-M14) included another seven frame skeletons with a fixed length of $35 \mathrm{~m}$, a fixed width of $35 \mathrm{~m}$, and heights varying from $(7 \times 3.5=24.5 \mathrm{~m})$ to $(13 \times 3.5=45.5 \mathrm{~m})$ with the previous 14 temperature-change loading cases, as shown in Table $\mathbf{1}$.
Table 2 shows the maximum structural analysis output forces (axial loads and bending moments) for model M1 for all loading cases U1-U14. Table 3 shows the maximum structural analysis output forces (axial loads and bending moments) for models M1-M7 for loading case U3.

Table 4 shows the maximum structural analysis output forces (axial loads and bending moments) for models M8M14 for loading case U3.

Table 3. Structural Analysis Results of Models M1-M7 for Loading Case U3

\begin{tabular}{|c|c|c|c|c|c|}
\hline Model No. & Loading Case & $\begin{array}{c}\text { Maximum Axial Load } \\
\text { (+ Compression, - Tension) } \\
\mathbf{A F}_{\max } \text { (Ton) }\end{array}$ & Beam Location & $\begin{array}{l}\text { Maximum Bending Moment } \\
\text { BM }_{\max } \text { (ton.m) }\end{array}$ & Column Location \\
\hline M2 & \multirow{5}{*}{ U3 } & -20.24 & \multirow{5}{*}{ Slab of ground floor } & $14.7,-8.9$ & \multirow{5}{*}{ Ground floor } \\
\hline M3 & & -23.42 & & $15.95,-9.5$ & \\
\hline M5 & & -27.4 & & $18.1,-10.8$ & \\
\hline M6 & & -29.5 & & $18.5,-10.9$ & \\
\hline M7 & & -33.9 & & $20.1,-11.2$ & \\
\hline
\end{tabular}

Table 4. Structural Analysis Results for Models M8-M14 for Loading Case U3

\begin{tabular}{|c|c|c|c|c|c|}
\hline Model No. & Loading case & $\begin{array}{c}\text { Maximum Axial Load } \\
\text { (+ Compression, - Tension) } \\
\mathbf{A F}_{\max } \text { (Ton) }\end{array}$ & Beam Location & $\begin{array}{l}\text { Maximum Bending Moment } \\
\qquad \mathbf{B M}_{\max } \text { (ton.m) }\end{array}$ & Column Location \\
\hline M8 & \multirow{7}{*}{$\mathrm{U} 3$} & -17.4 & \multirow{7}{*}{ Slab of ground floor } & $13.4,-8.2$ & \multirow{7}{*}{ Ground floor } \\
\hline M9 & & -17.4 & & $13.4,-8.2$ & \\
\hline M10 & & -17.4 & & $13.4,-8.2$ & \\
\hline M11 & & -17.4 & & $13.4,-8.2$ & \\
\hline M12 & & -17.4 & & $13.4,-8.2$ & \\
\hline M13 & & -17.4 & & $13.4,-8.2$ & \\
\hline M14 & & -17.4 & & $13.4,-8.2$ & \\
\hline
\end{tabular}

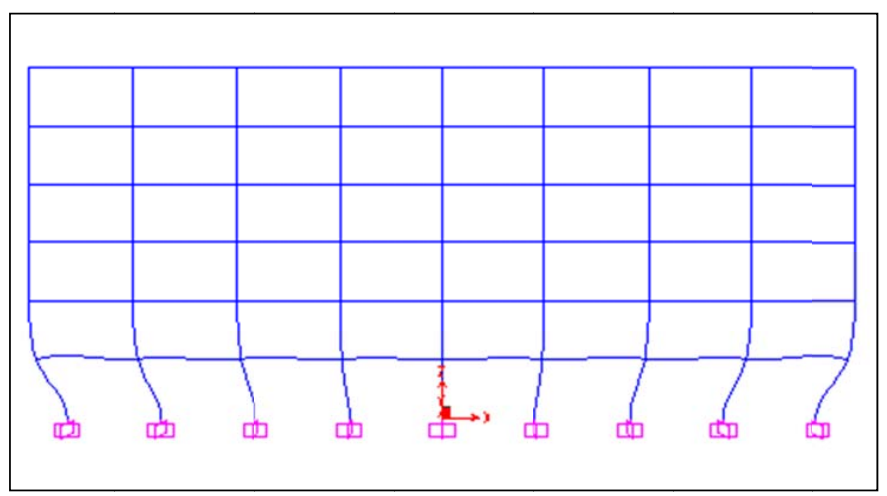

Fig. (1). Deformation shape of model M2 - U5 $(\mathrm{T}=+30)$ loading case. 
The analytical results of the study models show compatible deformation shapes and compatible output force diagrams. Fig. (1) shows the deformation shape of one of the 2D frames of model M2 subject to loading case U5 $(\mathrm{T}=+30)$, with the tendency of the frame to expand in the upper part and the resistance of the foundation against this expansion.

These deformations result in greater internal forces in the beams and columns of the ground floor, as shown in Fig. (2) (compression axial force) and Fig. (3) (bending moments).

Fig. (4) shows the deformation shape of one of the 2-D frames of model M2 subject to loading case U12 ( $\mathrm{T}=-30)$, with the tendency of the frame to contract in the upper part and the resistance of the foundation against this contraction.

These deformations result in higher internal forces in the beams and columns of the ground floor, as shown in Fig. (5) (tension axial force) and Fig. (6) (bending moments). Significance calculations on all models reveal that the most affected members under member-temperature loading are the beams and columns of the first floor above the foundation. At higher levels, direct forces decrease considerably and disappear [14].

\subsection{Section-Gradient-Temperature Loading Case}

Model M1 from the first study group was selected for the section gradient-temperature loading case. The thermal load was applied gradually on the sections of the façade and roof members of the skeleton of model M1. The model was analyzed for four loading cases related to total inside and outside temperature change (U15:T $=+10, \mathrm{U} 16: \mathrm{T}=+20, \mathrm{U} 17: \mathrm{T}=-$ 10, U18:T=-20 degrees Celsius). Samples of the most important structural analysis results are shown in Table $\mathbf{5}$.

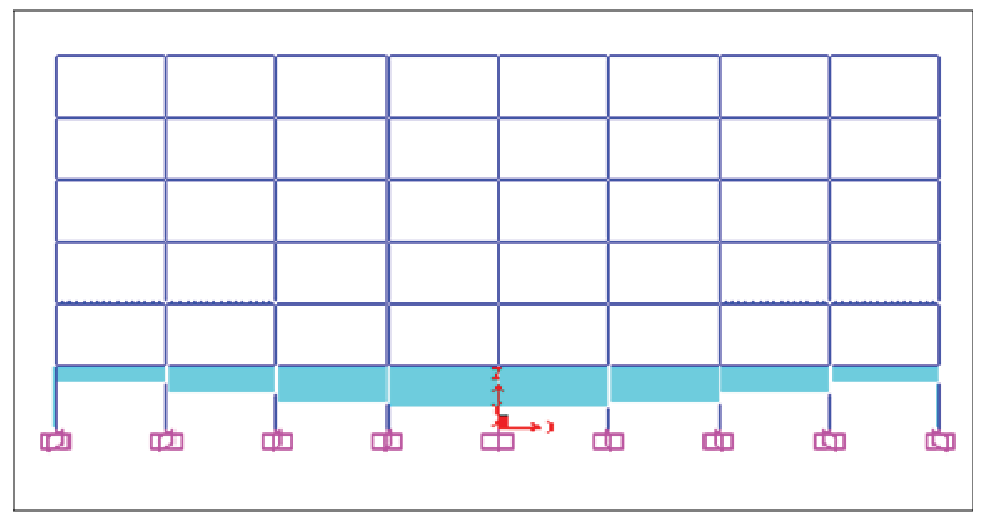

Fig. (2). Axial force diagram of Model M2 - U5 loading case.

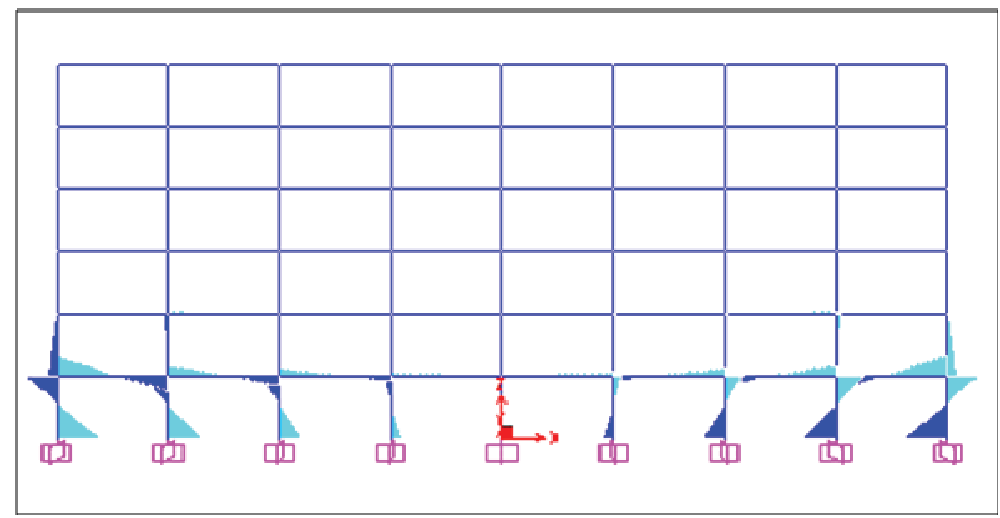

Fig. (3). Bending moment diagram of Model M2 - U5 loading case.

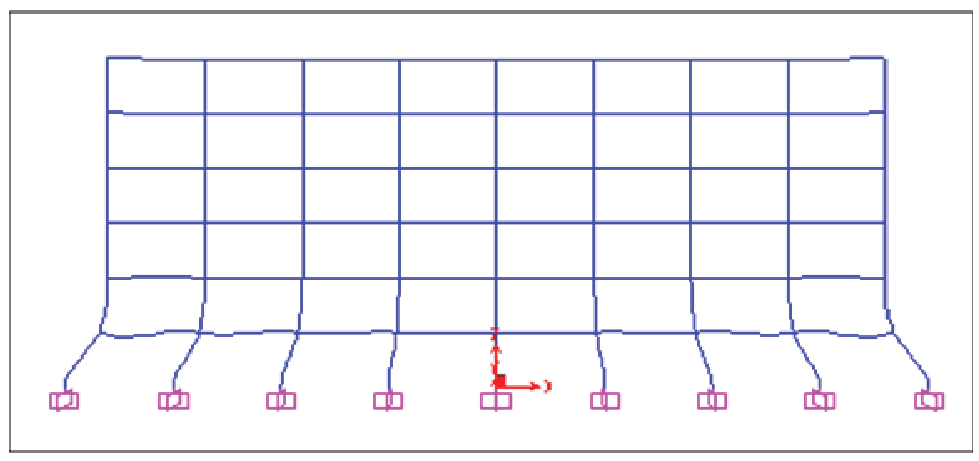

Fig. (4). Deformation shape of model M2 - U12 ( $\mathrm{T}=-30)$ loading case. 
Table 5. Structural Analysis Results of Model M1 (Section Gradient-Loading Cases U15-U18)

\begin{tabular}{|c|c|c|c|c|c|}
\hline Column Location & $\begin{array}{l}\text { Maximum Bending Moment } \\
\text { BM }_{\max } \text { (ton.m) }\end{array}$ & Beam Location & $\begin{array}{c}\text { Maximum Axial Load } \\
\text { (+ Compression, - Tension) } \\
\text { AF }_{\max } \text { (Ton) }\end{array}$ & Loading Case & Model No \\
\hline \multirow{4}{*}{ 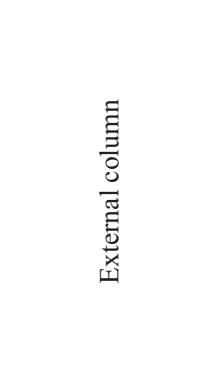 } & 3 & \multirow{4}{*}{ Beam of the level before roof } & 0.83 & $\begin{array}{c}\text { U15 } \\
\mathrm{T}=10\end{array}$ & \multirow{4}{*}{$\bar{\Sigma}$} \\
\hline & 5.9 & & -1.5 & $\begin{array}{c}\text { U16 } \\
\mathrm{T}=20\end{array}$ & \\
\hline & $3-$ & & -0.54 & $\begin{array}{c}\mathrm{U} 17 \\
\mathrm{~T}=-10\end{array}$ & \\
\hline & -5.9 & & -1.3 & $\begin{array}{c}\text { U18 } \\
\mathrm{T}=-20\end{array}$ & \\
\hline
\end{tabular}

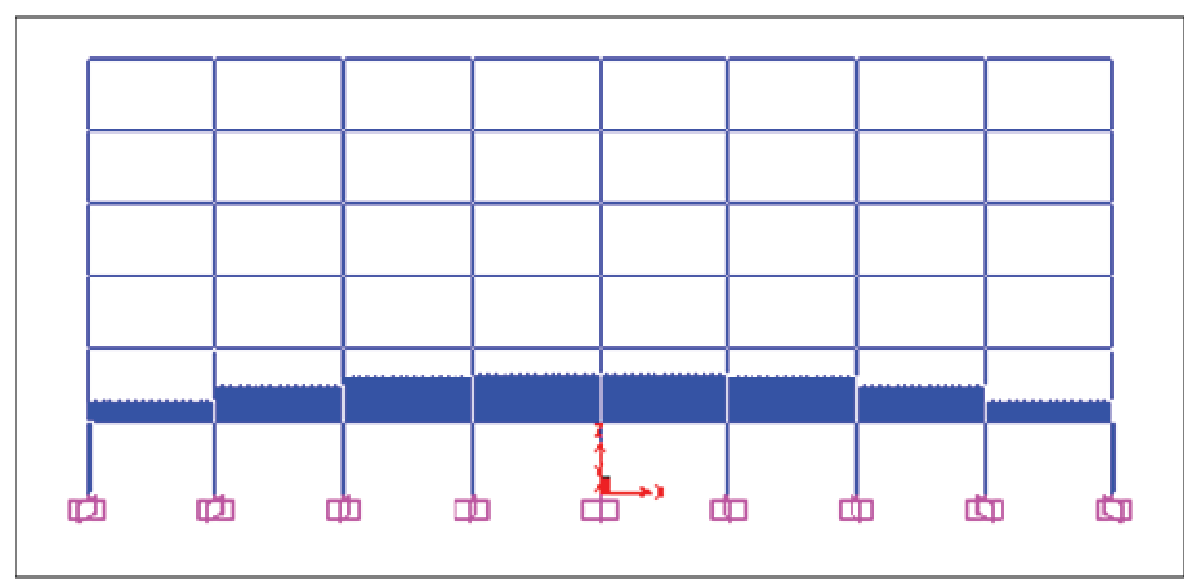

Fig. (5). Axial force diagram of Model M2 - U12 loading case.

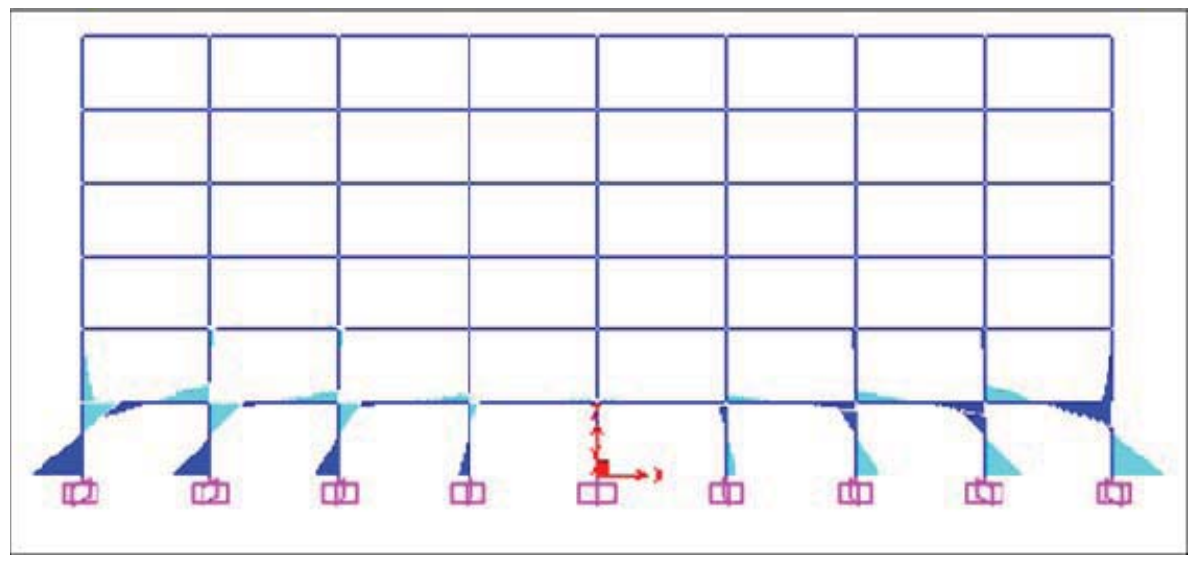

Fig. (6). Bending moment diagram of Model M2 - U12 loading case.

It can be observed that the most affected members are the beams of the upper two levels, in addition to the outer columns. Fig. (7) shows the bending moment diagram of one of the 2-D frames subjected to the U15 loading case $(\mathrm{T}=+10)$.

Fig. (8) shows the axial force diagram of one of the 2-D frames subjected to the U15 loading case $(\mathrm{T}=+10)$. It is also apparent that the output forces and the moment values are small and sometimes negligible compared to the results of the member-temperature loading case study.

\section{CONCLUDING REMARKS}

In the member-temperature change loading case, first, only members such as beams and columns of the lowest two stories are substantially affected. These elements should be designed for additional shear, bending moment, and axial forces related to thermal loading in addition to other gravity and lateral loadings. Second, no matter how high the structure is, the greater the length or width, the greater are the force values on the affected members. A temperature in- 


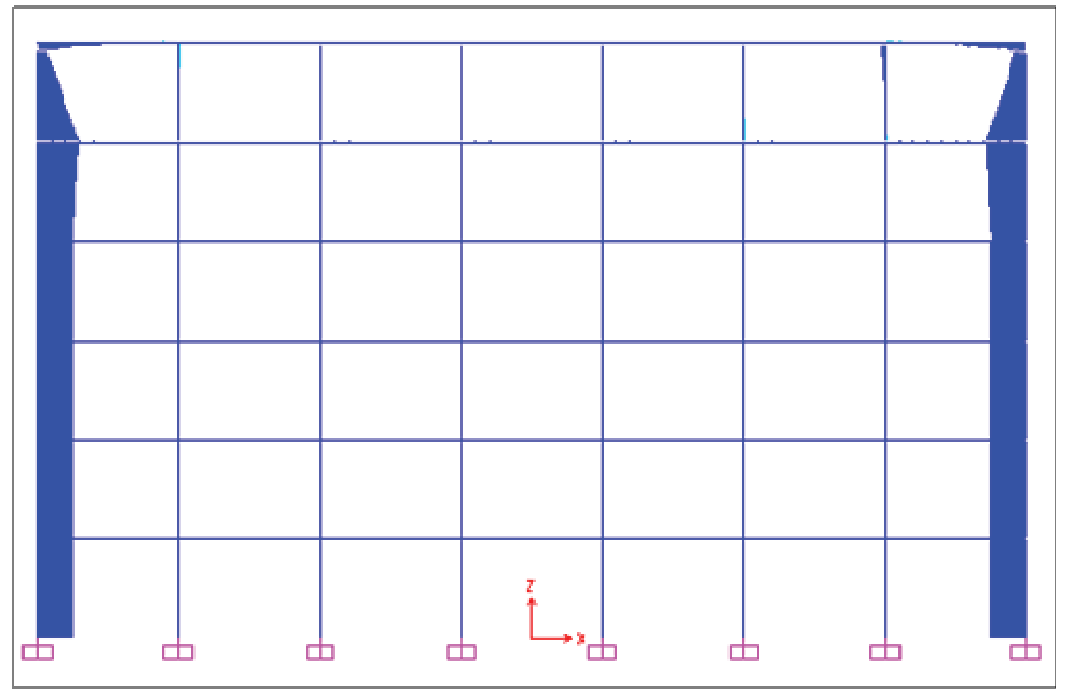

Fig. (7). Bending moment diagram of Model M1 - U15 loading case.

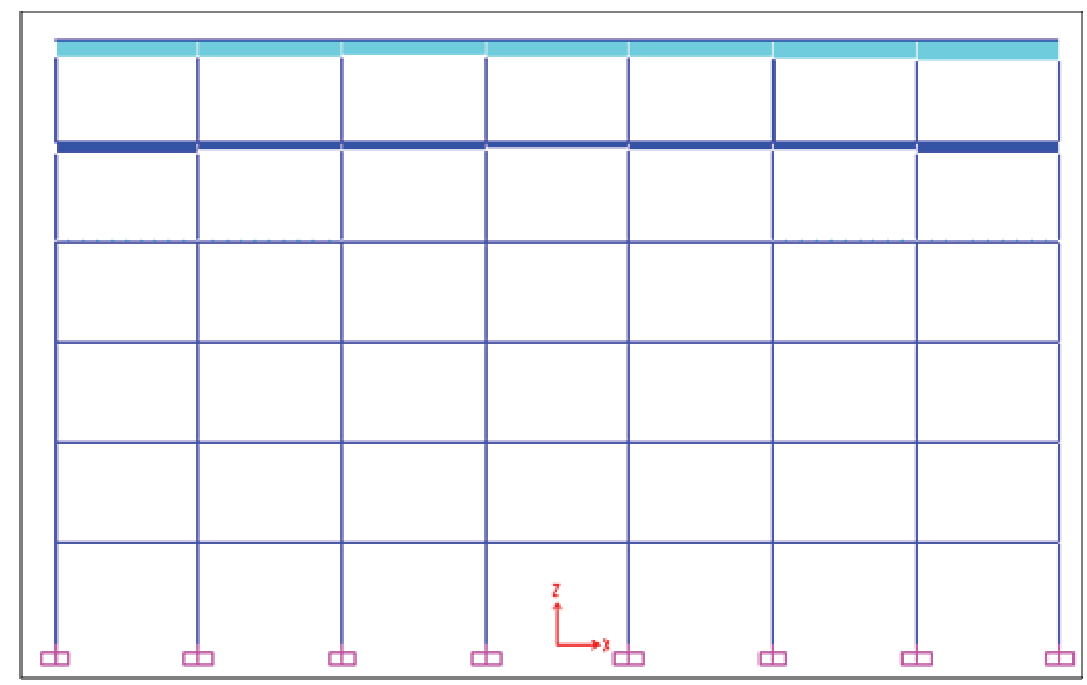

Fig. (8). Axial force diagram of Model M1 - U15 loading case.

crease results in increasing the forces on the affected members almost linearly, meaning that reducing temperatures by recently imposed insulation systems (by governmental and professional establishments) might reduce temperature forces. Temperature loading results in important output forces even in structures as short as $30 \mathrm{~m}$. These results might conflict with design standards that assume a maximum allowable length value without consideration of thermal loading. However, design standards depend not only on mathematical studies, but on real observations and good engineering judgment. Structures with greater than usual length should be treated carefully using analytical models. In the section gradient-temperature loading case, the most affected members are the beams of the upper two levels, in addition to the facade columns. However, the output forces and moment values are small and sometimes negligible compared with the results of the member-temperature loading case, especially in normal building structures. Other special purpose structures such as chimneys or cooling towers require special investigation.

\section{CONFLICTS OF INTEREST}

The authors confirm that this article content has no conflicts of interest.

\section{ACKNOWLEDGEMENT}

This research work was carried out at the University of Dammam, Saudi Arabia. The authors would like to thank the Engineering Department Administration for allowing using all needed facility to perform research work.

\section{REFERENCES}

[1] Y. Zandi, O. Burnaz, and A. Durmuş, "Fire analysis of reinforced concrete beams with 2-D plane stress concrete model", Res. J. Appl. Sci. Eng. Tech., vol. 5, no. 2, pp. 398-404, 2013.

[2] A. S. Usmani, J. M. Rotter, S. Lamont, A. M. Sanad, and M. Gillie, "Fundamental principles of structural behavior under thermal effects", Fire Safl J., vol. 36, pp. 721-744, 2001.

[3] F. J. Vecchio, and J. A. Sato, "Thermal gradient effects in reinforced concrete frame structures", ACI Struct. J., pp. 262-275, May-June 1990. 
[4] J. H. Hsu, and C. S. Lin, "Residual bearing capabilities of fireexposed reinforced concrete beams", Int. J. Appl. Sci. Eng., vol. 4, no. 2, pp. 151-163, 2006.

[5] F. J. Vecchion, N. Agostinoa and B. Angelak, "Reinforced concrete slabs subjected to thermal loads", Can. J. Civil Eng. vol. 20, pp. 741-753, 1993.

[6] W. Yin, H. Jiang, L. Zou, H. Liu, and J. Zou, "Effect analysis of temperature in the large continuous rigid frame bridge", Int. Confer. Green Build. $\square$ Mater Civil Eng. (GBMCE), 2011, Shangri-La, China. 2011.

[7] D. Li, "Design calculation and analysis of long structure considering the effects of visco-elastic stresses of hydration heat", J. Eng. Mech. vol. 24, no. 8, pp. 105-110, 2007.

[8] Z. Yang, L. Zhao, P. Zhang, and Y. Xing, "Research on temperature stress of annular super-long frame structure by finite element method, J. Adv. Mater Res., vol. 639-640, no. 1, pp. 1200-1205, 2013.
[9] J. Case, L. Chilver, and C. T. F. Ross, Strength of Materials and Structures, $4^{\text {th }}$ ed, Arnold, London, 1999.

[10] O. C. Zienkiewicz, and R. L. Taylor, The Finite-Element Method, vol. $1,5^{\text {th }}$ ed, The Basis, Butterworth-Heinemann, Woburn, MA, 2000.

[11] O. C. Zienkiewicz, and R. L. Taylor, The Finite-Element Method, vol. 2, $5^{\text {th }}$ ed, Solid Mechanics, Butterworth-Heinemann, Woburn, MA, 2000.

[12] M. K. Badrah, "Design of concrete structures for temperature loading", In: Proceedings, First International Conference of Concreting and High-Performance Concrete, American Concrete Institute, September 28-October 1, 2003, Kuwait.

[13] ACI 224.3R-95, "Joints in concrete construction", American Concrete Institute, Farmington Hills MI, USA, 2001.

[14] M. K. Badrah, Computer-Aided Analysis and Design of Structures, King Saud University, Riyadh, KSA, 2010.

Received: June 13, 2013

Revised: August 27, 2013

Accepted: September 03, 2013

(C) Badrah and Jadid; Licensee Bentham Open.

This is an open access article licensed under the terms of the Creative Commons Attribution Non-Commercial License (http://creativecommons.org/licenses/ by-nc/3.0/) which permits unrestricted, non-commercial use, distribution and reproduction in any medium, provided the work is properly cited. 